Service social

\title{
L'intervention interculturelle par Gisèle Legault et collab., Montréal, Gaëtan Morin éditeur, 2000, 364 pages.
}

\section{Nicole Boucher}

Volume 47, numéro 3-4, 1998

Enfance : enjeux et réalités 2000

URI : https://id.erudit.org/iderudit/706805ar

DOI : https://doi.org/10.7202/706805ar

Aller au sommaire du numéro

Éditeur(s)

École de service social de l'Université Laval

ISSN

1708-1734 (numérique)

Découvrir la revue

Citer ce compte rendu

Boucher, N. (1998). Compte rendu de [L'intervention interculturelle par Gisèle Legault et collab., Montréal, Gaëtan Morin éditeur, 2000, 364 pages.] Service social, 47(3-4), 349-350. https://doi.org/10.7202/706805ar d'utilisation que vous pouvez consulter en ligne.

https://apropos.erudit.org/fr/usagers/politique-dutilisation/ 
SUGGESTION DE LECTURE

\section{L'intervention interculturelle}

Gisèle LEGAULT et collab.

Montréal, Gaëtan Morin, 2000, 364 p.

Sous la direction de Gisèle Legault, professeure à l'École de service social de l'Université de Montréal, douze auteurs ont contribué à ce livre publié dans la collection "Pratiques professionnelles » chez Gaëtan Morin. Les sujets traités sont variés, allant du processus migratoire aux problématiques particulières et aux modes d'intervention du Québec, en passant par la société multiethnique, la diversité des valeurs et des croyances, les mécanismes d'inclusion et d'exclusion ainsi que les parcours. L'ensemble est assez bien construit, offrant à la fois cadre théorique et outils méthodologiques précieux pour l'intervention auprès de la clientèle d'immigration récente (Gisèle Legault et Ghislaine Roy), auprès des réfugiés (Marie Brault), auprès des jeunes en difficulté (Michèle Chiasson-Lavoie et Marie-Lyne Roc) et des adolescents (Ghislaine Legendre), auprès des femmes immigrantes et de leur famille (Ginette Aumont, Nicole Guindon et Gisèle Legault), de même que pour l'intervention interculturelle en ethnopsychiatrie (Marie-Élizabeth Pierzo et Gisèle Legault).

Signalons la contribution importante de madame Margalit CohenEmerique, psychologue française, qui ne se réduit pas à son article sur l'approche interculturelle auprès des migrants; elle traverse en effet tout le livre, car madame Cohen-Emerique est considérée comme la référence de base en relations et communications interculturelles. 
Nous voyons donc ce livre comme une première contribution québécoise importante vers de nécessaires conceptions multiples de l'intervention sociale auprès de migrants et de réfugiés.

Comme nous estimons que l'intervention en contexte interculturel ne s'adresse pas seulement aux personnes vivant un processus migratoire, nous regrettons l'absence d'autres sujets tout aussi importants dans le domaine, par exemple la diversité raciale et l'intervention antiraciste, le service social international.

En somme, je recommande fortement la lecture de ce livre aux travailleurs sociaux, et surtout à ceux qui interviennent peu fréquemment dans leur pratique "en contexte interculturel ». Ils y trouveront des références de base, une bonne synthèse de connaissances québécoises actuelles sur le sujet et des outils de travail pertinents. On devrait toutefois compléter cette lecture par d'autres livres présentant une autre conception de l'intervention, si possible moins culturaliste.

Nicole BOUCHER

Professeure

École de service social

Université Laval 